\title{
Preventing Foodborne Illness: Clostridium botulinum ${ }^{1}$
}

\author{
Keith R. Schneider, Mickey E. Parish, Renée M. Goodrich and Taylor Cookingham²
}

\section{What is Clostridium botulinum?}

Botulism is caused by the nerve toxins produced by the bacterium Clostridium botulinum, often resulting in a serious paralytic condition that can lead to death.

Clostridium botulinum is ubiquitous in nature, but most prevalent in soil and water. Although the bacteria and spores are harmless, the production of toxins is what leads to illness and death. There are three types of botulism, each named accordingly to the mode of acquisition of the toxin. Foodborne botulism results from the ingestion of the botulinum toxin, while wound botulism is a result of organisms growing and producing the toxin in the wound. Infant botulism is the most common, caused by $C$. botulinum producing toxins in the intestine. The Centers for Disease Control and Prevention (CDC) suggests a fourth type of botulism, of which no origin can be determined and results from the colonization of the intestines of adults and children. These cases of botulism have been caused by botulinum neurotoxins produced by non $C$. botulinum species.

\section{What causes Clostridium botulinum foodborne illness?}

There are seven strains of $C$. botulinum, based on differences in antigenicity among the toxins, each characterized by its ability to produce a protein neurotoxin, enterotoxin, or haemotoxins. Types A, B, $\mathrm{E}$, and $\mathrm{F}$ cause botulism in humans, while types C-alpha, C-beta, and D cause botulism in animals and birds. Type $\mathrm{G}$ was identified in 1970 but has not been determined as a cause of botulism in humans or animals.

The organisms are characterized by their straight, slightly curved, Gram-positive, motile, anaerobic rods, which produce heat-resistant spores. The spores become activated in a low acid (less than 4.6), anaerobic environment with temperatures ranging from $40^{\circ} \mathrm{F}$ to $120^{\circ} \mathrm{F}$, having high moisture content, and lacking competing bacterial flora. According to

1. This document is FSHN04-06, one of a series of the Food Science and Human Nutrition Department discussing common foodborne pathogens of interest to food handlers, processors, and retailers; Florida Cooperative Extension Service, Institute of Food and Agricultural Sciences, University of Florida. Date Published: November 2004. Please visit the EDIS Web site at http://edis.ifas.ufl.edu.

2. K.R. Schneider, assistant professor, Food Science and Human Nutrition Department, Gainesville; Mickey E. Parish, professor, R.M. Goodrich, assistant professor, Citrus REC, Lake Alfred; and Taylor Cookingham, student, Food Science and Human Nutrition Department, Cooperative Extension Service, Institute of Food and Agricultural Sciences, University of Florida, Gainesville, FL 32611.

Copyright Information

This document is copyrighted by the University of Florida, Institute of Food and Agricultural Sciences (UF/IFAS) for the people of the State of Florida UF/IFAS retains all rights under all conventions, but permits free reproduction by all agents and offices of the Cooperative Extension Service and the people of the State of Florida. Permission is granted to others to use these materials in part or in full for educational purposes, provided that full credit is given to the UF/IFAS, citing the publication, its source, and date of publication.

The Institute of Food and Agricultural Sciences (IFAS) is an Equal Employment Opportunity - Affirmative Action Employer authorized to provide research, educational information and other services only to individuals and institutions that function without regard to race, creed, color, religion, age, disability, sex, sexual orientation, marital status, national origin, political opinions or affiliations. For information on obtaining other extension publications, contact your county Cooperative Extension Service office. Florida Cooperative Extension Service/Institute of Food and Agricultural Sciences / University of Florida / Larry R. Arrington, Interim Dean 
the CDC, there were 169 reported cases of botulism in 2001: 33 foodborne, 112 infant, and 23 resulting from wound botulism.

Although the incidence of $C$. botulinum in the United States is rare, due to increasing knowledge and education in proper storage and handling of foods, the bacterium and its spores are ubiquitous and often unavoidable in nature.

Foodborne botulism is caused by the ingestion of toxins produced by the bacterium in foods that have not been properly handled or canned. The toxin is heat labile and is often present in canned vegetables, meat, and seafood products.

Infant botulism is the most common form of botulism. It is caused by the ingestion of $C$. botulinum spores which produce a neurotoxin in the intestine. According to a report by the CDC, reviewing the epidemiology of botulism in the United States, infants hospitalized with botulism have a pattern of higher birth weights, "and their mothers tend to be white, older, and better educated."

Wound botulism is the rarest, and occurs when C. botulinum infects a wound and produces toxins that are carried through the rest of the body via the bloodstream.

The fourth class of botulism consists of cases which an origin of cause can not be determined. Several theories suggest answers to the cause, such as surgical procedures on the gastrointestinal tract that may have altered the flora of the intestine, resulting in a favorable environment for the bacterium to grow. Documents suggest cases of botulism associated with clostridia other than $C$. botulinum, including adult and infant botulism associated with $C$. baratii, caused by Type F neurotoxin ${ }^{1}$.

\section{What are the symptoms associated with Clostridium botulinum?}

Foodborne botulism produces symptoms within 6 hours, although most begin within 12 to 36 hours, and some can even start after two weeks. Symptoms associated with foodborne botulism include double and blurred vision, slurred speech, difficulty swallowing, dry mouth, diarrhea, nausea, and muscle weakness that descends through the body, starting at the shoulders and ending at the feet. The severity of botulism parallels the type of toxin. Type A botulism requires hospitalization for about $67 \%$ of patients, followed by Type B hospitalizing 52\% of patients and $39 \%$ for Type $E^{1}$. Although there is a five percent mortality rate, due to paralysis of motor and autonomic nerves, recovery is possible, although continued shortness of breath and fatigue is inevitable. Deaths that occur within the first two weeks of botulism are often the result of pulmonary or systematic infection and failure to recognize the disease. Often the symptoms of foodborne botulism are mistaken for symptoms associated with stroke, chemical intoxication, myasthenia gravis, and Guillain-Barre syndrome. Tests such as brain scans, spinal tap exams, nerve conduction exams, electromyography (EMG), and a tensilon exam can distinguish the above diseases from botulism.

Infant botulism, the most common form of botulism, occurs when an infant ingests the spores of C. botulinum which colonize the intestinal tract and produce toxins. Infants diagnosed with botulism may appear lethargic, constipated, poor feeding patterns, and have a weak cry. These symptoms are a result of slow muscle paralysis caused by the bacterial neurotoxin. If proper hospitalization is provided, botulism may progress for another one to two weeks followed by a stabilization period of two to three weeks. The mortality rate is lower than that of foodborne botulism, producing about $1.3 \%$ deaths. In addition, about five percent of Sudden Infant Death Syndrome (SIDS) cases have been linked to infant botulism.

\section{Who is at risk?}

Although foodborne botulism is rare and one of the least common of the foodborne diseases, $C$. botulinum can infect all persons, since infection may result from ingestion of contaminated foodstuffs. In fact, it takes only a small amount of toxin to cause illness. However, the immunocompromised, followed by the very young and old may suffer from more serious side affects.

Foodborne botulism is not spread from person to person. Instead, it requires that the toxin be ingested. 
Home canned products, especially low acid food products attribute to most of the cases of foodborne botulism. On a commercial scale, improperly handled food products have also contributed to outbreaks.

\section{What foods have been commonly associated with Clostridium botulinum?}

Clostridium botulinum is present in the water and soil, so potentially any food which comes into contact with such vectors presents a potential hazard. However, improperly home canned low acid vegetables and contaminated meats are usually the cause of foodborne botulism. Including foods such as canned asparagus, green beans, garlic in oil, corn, soups, ripe olives, tuna fish, sausage, luncheon meats, fermented meats, salad dressings, and smoked fish. Spores have also been found on the surfaces of vegetables and fruits.

During the canning process, foods undergo a hot fill process and oxygen is removed, leaving the food in an anaerobic environment. Certain foods, such as meat are able to bind oxygen to create an anaerobic environment. Home canning processes for low acid foods present an extremely high risk because time temperatures are often inadequate and cans or jars may not be evenly rotated.

Even cooking with oils and grease can create an anaerobic environment. In addition, fresh produce can be a source of foodborne botulism. Outbreaks stemming from the growth of the botulinum toxin from unrefrigerated cabbage have been documented.

Strains of $C$. botulinum can be mesophilic with growth between $55^{\circ} \mathrm{F}$ and $115^{\circ} \mathrm{F}$ and psychotrophic, with growth between $38^{\circ} \mathrm{F}$ and $110^{\circ} \mathrm{F}$. This means that strains can grow not only at room temperatures, but at normal refrigeration and higher temperatures. This makes it difficult to kill the toxins. If the proper temperature to kill the spores is not reached, the resulting environment can be perfect for growth and the production of neurotoxins.

Infant botulism has been linked to the ingestion of $C$. botulinum spores in honey, corn syrup, and other foods. The $C$. botulinum spores germinate, colonize and produce toxin in the intestinal tract of infants (intestinal toxemia botulism). Infants less than 1-year-old lack the proteins in their intestines needed to destroy either the vegetative or spore form of C. botulinum.

\section{What sanitation methods are used to prevent infection?}

Clostridium botulinum spores are extremely heat resistant, so while cooking at proper temperatures would destroy most foodborne pathogens, it does not destroy $C$. botulinum. While heat resistance is increased with higher $\mathrm{pH}$ and lower salt content medium, many of these spores can survive preservation methods which usually kill nonsporulating organisms. The CDC suggests that the main limiting growth factors for $C$. botulinum are temperature, $\mathrm{pH}$, water activity $\left(\mathrm{a}_{\mathrm{W}}\right)$, redox potential, food preservatives, and competing microorganisms.

While most bacterium cannot survive at a $\mathrm{pH}$ of 4.6 or below, some proteins such as soy and beef have protective agents which allow it to grow at a $\mathrm{pH}$ lower than 4.6. Low water activity inhibits the growth of $C$. botulinum which is why dehydrated foods and foods which are high in salt and/or sugar do not support the growth of the bacterium. Food preservatives such as nitrites, sorbic acid, phenolic antioxidants, polyphosphates, and ascorbates as well as lactic acid bacteria inhibit the growth of $C$. botulinum.

Most outbreaks of foodborne botulism are the result of poor home canning mechanisms. Proper time, temperature, and pressure required to destroy spores as well as proper storage methods of home canned food products is necessary to ensure the safety of the consumer. According to the $\mathrm{CDC}$, a pressure cooker can be used for home canning purposes merely because it can reach temperatures higher than boiling point $\left(212^{\circ} \mathrm{F}\right)$ which is necessary to kill the spores.

While the botulinum spores are heat stable, the toxin itself is heat-labile, so heating a food to $176^{\circ} \mathrm{F}$ for 10 minutes before consumption can greatly reduce the risk of illness. 
The suggestions below are good examples of how to prevent foodborne $C$. botulinum:

- If consuming home canned foods, heat low acid foods to $176^{\circ} \mathrm{F}$ or boiling for 10 minutes and corn, spinach and meats for 20 minutes before consumption to reduce the risk of illness.

- Oils infused with garlic or herbs should be properly refrigerated $\left(45^{\circ} \mathrm{F}\right)$ to prevent the growth of $C$. botulinum spores.

- Canned food products, both home and commercial, should be inspected before use. Cans with bulging or damaged lids, leakage, or off odors should not be used because growth of the bacteria can often produce a gas, causing the can to expand.

- Home canned foods should be canned in pressure cookers to ensure the proper time, temperature and pressure requirements to avoid the growth of the bacteria and spores.

- Although commercial food products have a low rate of botulism, read the label and throw out any and all damaged or expired cans.

- If canning meats, use nitrites or salt in the brine in addition to heat to reduce the growth of $C$. botulinum.

- Vacuum packaged meats should be refrigerated or properly stored in the freezer for extended use.

- Keep hot foods above $140^{\circ} \mathrm{F}$ and cold foods below $40^{\circ} \mathrm{F}$ to prevent the formation of spores.

- Wash hands, utensils, and food contact surfaces (FCS's) with hot soapy water after they touch raw meat or seafood, before food preparation, and after using the bathroom.

\section{Good practices for food product receiving, handling, processing and storage}

The FDA defines cGMPs in 21 CRF, Part 110. These cGMPs outline minimally required general sanitation requirements in FDA inspected food handling and processing facilities. It is recommended that more specific and stringent standard operating procedures (SOPs) be developed for individual facilities. In addition, the sanitation recommendations for food service and retail food facilities outlined in the FDA 2001 Food Code (FDA 2001) have been adopted into many state and local regulations. As there may be some variation in 2001 Food Code adoption, it is important that each facility check with the appropriate state and/or local regulatory authority. The Florida statues can be found at http://www.leg.state.fl.us/statutes, Title 33: Chapter 509.

In addition to setting and adhering to strict sanitation requirements in the facility, a retail establishment should also develop SOPs for receiving and storage of food products and ingredients. If food processing is being done, appropriate controls and requirements should be established and strictly adhered to. FDA 2001 Food Code outlines appropriate processing and cooking requirements for many food products processed in a retail facility. However, if certain high-risk food products (such as sushi, fresh juice, specialty meats, and others) are processed in the retail establishment, rather than in a more traditional processing facility, additional controls and the issuance of a variance by the regulatory authority is required before processing can occur (Food Code 3-502.11). The growing retail practice of cooking, preparing, and packaging foods traditionally processed in controlled plant environments raises safety concerns. Any processing of food at the retail level needs to be closely monitored.

As an establishment becomes cleaner, it becomes harder to detect foodborne pathogens. At this point, testing becomes more limited in its ability to prevent foodborne illness. This is why programs that promote and monitor the use of barriers and/or hurdles are so important. When instituted properly, these activities will reduce the risk of a foodborne illness. Nothing can be done to completely eliminate bacterial contamination short of vacuum sealing, irradiating, and storing all your products frozen. Since most consumers prefer a fresh product, programs should be implemented that reduce the probability of illness to a point that it is minuscule. 


\section{Receiving}

Specifications for receiving can be found in section 3-202.11 of the 2001 Food Code http://www.cfsan.fda.gov/ dms/foodcode.html. The following guidelines cover the basic points that should be addressed:

- Potentially Hazardous Food (PHF) should be at a temperature of $41^{\circ} \mathrm{F}$ or below when received, unless specified by law (e.g. milk, shellfish).

- PHFs that are received hot should be at a temperature of $140^{\circ} \mathrm{F}$ or above.

- PHF should be received with no evidence of temperature abuse such as evidence of thawing.

For recommendations that are more specific consult the 2001 Food Code http://www.cfsan.fda.gov/ dms/foodcode.html.

\section{Storage}

Once a product has been received and/or processed, it now will be displayed or stored. There are some general guidelines governing these practices as well.

- Frozen food should remain frozen until it is used.

- If frozen food is displayed in a refrigerated case and allowed to thaw, the food should remain at $41^{\circ} \mathrm{F}$ or below.

- Frozen food should be thawed at a temperature of $41^{\circ} \mathrm{F}$ or below or under running water at a temperature of $70^{\circ} \mathrm{F}$ or below.

- Lastly, the product can be thawed as part of the cooking process.

- Product must be cooled adequately. Refer to sections 3-501.14 and 3-501.15 of the 2001 Food Code http://www.cfsan.fda.gov/ dms/foodcode.html.

- Cooked product should be maintained above $140^{\circ} \mathrm{F}$ while displayed and stored at or under $41^{\circ} \mathrm{F}$.
- Properly label all stored product.

\section{Personal hygiene}

Wash your hands! The major cause of foodborne illness in retail establishment comes from poor personal hygiene, particularly a lack of proper hand washing. Dirty hands can contaminate food. Although hands may look clean, the bacteria that cause illness are too small to be seen. Therefore, whenever you are preparing food and you come in contact with items that are not part of the assembly process, rewash your hands. The same is true even when wearing gloves.

THERE IS NO FIVE SECOND RULE WHEN IT COMES TO FOOD SAFETY!

Millions of bacteria and other germs can be transferred on contact. Here is a list of times when should you wash your hands:

- before handling, preparing, or serving food

- before handling clean utensils or dishware

- after using the restroom

- after touching your face, cuts, or sores

- after smoking, eating, or drinking

- after handling raw meat - especially poultry

- after touching unclean equipment, working surfaces, soiled clothing, soiled wiping cloths, etc.

- after collecting and taking out the garbage

\section{What is the proper procedure for hand washing?}

1. Wet your hands with warm water

2. Apply soap and wash your hands for 20 seconds

3. Rinse and dry with a single-use paper towel

4. Use the paper towel to shut off the water 


\section{References}

Anon. "Botulism." Centers for Disease Control, http://www.cdc.gov/ncidod/dbmd/diseaseinfo/ botulism_t.htm (accessed 12/22/04).

Anon. "Botulism." New York State Dept. of Health, http://www.health.state.ny.us/ (accessed 12/22/04).

Bad Bug Book "Clostridium botulinum." U.S. Food and Drug Administration, http://vm.cfsan.fda.gov/ mow/chap2. html.

Kim, J. "Botulism." E-medicine.

http://www.emedicine.com/emerg/topic64.htm (accessed 12/22/04). 